\title{
Comparison between electron and neutron Compton scattering studies
}

\author{
Raymond Moreh ${ }^{1, a}$, Yacov Finkelstein ${ }^{2}$ and Maarten Vos $^{3}$ \\ ${ }^{1}$ Physics Department, Ben-Gurion University of the Negev, Beer-Sheva, 84105, Israel \\ ${ }^{2}$ Nuclear Research Center-Negev, Beer-Sheva, 84190, Israel \\ ${ }^{3}$ Atomic and Molecular Physics Laboratories, Australian National University, Canberra, Australia
}

\begin{abstract}
We compare two techniques: Electron Compton Scattering (ECS) and neutron Compton scattering (NCS) and show that using certain incident energies, both can measure the atomic kinetic energy of atoms in molecules and solids. The information obtained is related to the Doppler broadening of nuclear levels and is very useful for deducing the widths of excited levels in many nuclei in self absorption measurements. A comparison between the atomic kinetic energies measured by the two methods on the same samples is made. Some results are also compared with calculated atomic kinetic energies obtained using the harmonic approximation where the vibrational frequencies were taken from IR/Raman optical measurements. The advantages of the ECS method are emphasized.
\end{abstract}

\section{Introduction}

The use of electron scattering can in many cases simulate neutron scattering especially when the de Broglie wave lengths of the incident electrons and the neutrons are of nearly the same magnitude. A most interesting case occurs when the de Broglie wavelength is much shorter than inter-atomic dimensions. In such cases, for $135^{\circ}$ deflection, the incident particle scatters from a single atom of the molecular system as if the single atom is free and not bound to the molecule. The scattering in this case is termed Electron Compton Scattering (ECS) [1] in a similar manner to Neutron Compton Scattering (NCS) [2]. For the electrons the incident energies should be $\mathrm{E}_{\mathrm{e}} \geq 1 \mathrm{keV}$, hence the de Broglie wave length $\lambda_{\mathrm{e}} \leq 0.38 \AA$, while for neutrons $E_{n} \geq 5 \mathrm{eV}$ and $\lambda_{n} \leq 0.13 \AA$ (depending on the neutron energy filter of the spectrometer) [3].

In the literature both the ECS and NCS methods were used for measuring atomic kinetic energies. Because of the high n-H scattering cross section, the NCS method is best suited for studying the kinetic energy of Hydrogen in $\mathrm{H}$-containing systems such as $\mathrm{H}_{2} \mathrm{O}$ and $\mathrm{CH}_{2}$ using incident neutron energies of $10 \mathrm{eV}$ to $200 \mathrm{eV}$ [3].

In spite of the small e-H scattering cross section (which follows the Rutherford $Z^{2}$ formula), the ECS method was used for studying several targets at energies between $\sim 1$ $6 \mathrm{keV}$ such as $\mathrm{H}_{2} \mathrm{O}$ [4], $\mathrm{CH}_{2}$ [5], $\mathrm{NH}_{3}$ [6], $\mathrm{CH}_{4}$ [7] as well as graphite and diamond [8] and $\mathrm{SiO}_{2}$ at energies up to $40 \mathrm{keV}$. The measured atomic kinetic energies using the NCS and ECS techniques were found to be in fair agreement with each other and with calculated values as will be shown below. In the present work we discuss few cases in which the atomic kinetic energies were measured using both methods.

\footnotetext{
a Corresponding author: moreh@bgu.ac.il
}

\subsection{Effect on nuclear level widths}

The measurement of atomic kinetic energies is central for the determination of the atomic zero-point energies in molecules, solids and also in nuclear physics studies. The Doppler width $\Delta_{\mathrm{r}}$ of nuclear levels is related to the atomic kinetic energy $\mathrm{K}_{\mathrm{e}}$ by: $\Delta_{\mathrm{r}}=\left(4 \mathrm{E}_{\mathrm{r}}^{2} \mathrm{~K}_{\mathrm{e}} / 3 \mathrm{Mc}^{2}\right)^{1 / 2}$ where $\mathrm{M}$ is the nuclear mass, c the velocity of light, and $E_{r}$ the excitation energy of the nuclear level.

This point is remarkable in view of the relation between $\mathrm{K}_{\mathrm{e}}$ and $\Gamma_{\mathrm{o}}$ (the transition width to the ground state of the nuclear level); it was illustrated for the first time in Ref. [9] in the $6.92 \mathrm{MeV}$ level in ${ }^{16} \mathrm{O}$. One way of measuring $\Gamma_{0}$ is to use the method of nuclear self-absorption $[10,11]$ which is strongly dependent on $\Delta_{\mathrm{r}}$ of the level and hence on $\mathrm{K}_{\mathrm{e}}$. Here the measurement was carried out [9] using a bremsstrahlung beam and a liquid water $\left(\mathrm{H}_{2} \mathrm{O}\right)$ sample, at $\mathrm{T}=295 \mathrm{~K}$. The deduced value of $\Gamma_{\mathrm{o}}(6.92 \mathrm{MeV})$ depends on $\mathrm{K}_{\mathrm{e}}\left({ }^{16} \mathrm{O}\right)$ in water. If one uses the correct value, $\mathrm{K}_{\mathrm{e}}(\mathrm{O})=53.0 \mathrm{meV}$ (obtained by accounting for the internal vibrations of $\mathrm{H}_{2} \mathrm{O}$ (see below)), the resulting value of $\Gamma_{0}(6.92 \mathrm{MeV})$ is $17 \%$ higher than that obtained when using the thermal value $\mathrm{K}_{\mathrm{e}}(\mathrm{O})=3 \mathrm{kT} / 2=38.7 \mathrm{meV}$ at $295 \mathrm{~K}$; this illustrates the important role of $\mathrm{K}_{\mathrm{e}}(\mathrm{O})$ for deducing $\Gamma_{\mathrm{o}}$ in a nuclear self absorption measurement.

Note that for metallic elements, $\Delta_{\mathrm{r}}$ may be calculated by using the Lamb procedure which views the atoms as Planck oscillators having a density of states (DOS) proportional to $v^{2}$ up to a cutoff frequency $v_{D}$ related to the Debye temperature $\theta_{\mathrm{D}}$ of the metal [12]. For such a system, an effective temperature $T_{e}$ is defined in terms of $\theta_{\mathrm{D}}$ and is related to the mean atomic kinetic energy by: $\mathrm{K}_{\mathrm{e}}$ $=3 \mathrm{kT}_{\mathrm{e}} / 2$. This method for calculating $\Delta_{\mathrm{e}}$ is not applicable 
to chemical compounds or to cases such as elemental Boron [10], diamond [8,13] and graphite [8,14] where one has to account for the complex phonon DOS.

In the following we illustrate the calculation of $\mathrm{Ke}(\mathrm{O})$ in a sample involving a carbonate $\left(\mathrm{CO}_{3}{ }^{--}\right)$which occurs in chemicals such as $\mathrm{Li}_{2} \mathrm{CO}_{3}, \mathrm{Na}_{2} \mathrm{CO}_{3}, \mathrm{CaCO}_{3}$, etc where $\mathrm{K}_{\mathrm{e}}(\mathrm{O})$ is nearly the same because the internal vibrations of the $\mathrm{CO}_{3}^{--}$group are almost unaffected by the weak ionic bonding to the metal partner e.g. $\mathrm{Li}^{+}$.

\section{Calculating atomic kinetic energies}

This calculation assumes the harmonic approximation and a decoupling between the three modes of motion: translation, rotation and vibration. In the solid phase, the translation and rotation turn into vibration and libration of the whole $\mathrm{CO}_{3}{ }^{--}$ion. The value of $\mathrm{K}_{\mathrm{e}}\left({ }^{16} \mathrm{O}\right)$ of $\mathrm{CO}_{3}{ }^{--}$is calculated by noting that $\mathrm{CO}_{3}$ is a planar molecule forming an equilateral triangle with the $\mathrm{O}$-atoms occupying the vertices while the $\mathrm{C}$-atom lie at the center. $\mathrm{K}_{\mathrm{e}}(\mathrm{O})$ is contributed by the external motions of vibration and libration of $\mathrm{CO}_{3}^{--}$, and its internal vibrations which consist of 6 normal modes, two of which are degenerate due to the symmetry of the molecule. The expression for the kinetic energy of ${ }^{16} \mathrm{O}$ may be written as:

$$
K_{e}(O)=S_{T} \frac{3}{2} k T_{t}+S_{R} \frac{3}{2} k T_{r}+\sum_{j=1}^{6} S_{j} \frac{h v_{j}}{2}\left(\frac{1}{e^{h v_{j} / k T}-1}+\frac{1}{2}\right)
$$

Where $S_{T}, S_{R}$ and $\mathrm{S}_{\mathrm{j}}$ are the energy fractions taken by the $\mathrm{O}$-atom in the external motion of vibration + libration and the internal vibration $\mathrm{j}(\mathrm{j}=1 \ldots 6)$. The fraction $S_{T}=$ $16 / 60$ is obtained from the mass ratio of $\mathrm{O}$ to $\mathrm{CO}_{3} ; S_{R}$ may be deduced classically using the $\mathrm{CO}_{3}$ geometry. The effective temperatures $T_{t}=h v_{t} / k$ and $T_{r}=h v_{r} / k$ account for the lattice vibration and librations of $\mathrm{CO}_{3} . \mathrm{S}_{\mathrm{j}}$ were calculated using standard methods of IR spectroscopy [15]. The input data were: the 6 experimental vibrational frequencies of $\mathrm{CO}_{3}^{--}$(Table 1) and the four force constants: $\mathrm{K}_{1}$ (bending of the O-C-O angle), $\mathrm{K}_{2}$ (C-O symmetric stretching) $\mathrm{K}_{3}$ (C-O asymmetric stretching) and $\mathrm{K}_{5}$ (restoring force which brings back the $\mathrm{C}-\mathrm{O}$ to the molecular plane) [16]. Using $\mathrm{S}_{\mathrm{j}}$ and eq. (1), $\mathrm{Ke}(\mathrm{O})$ and $\mathrm{Ke}(\mathrm{C})$ of $\mathrm{CaCO}_{3}$ were then evaluated (Table 2) which also shows the calculated $\mathrm{K}_{\mathrm{e}}$ values in $\mathrm{H}_{2} \mathrm{O}$ [16] and $\mathrm{O}_{2}$. In $\mathrm{CaCO}_{3}$ the internal and lattice frequencies (Table 1) were assumed to be those of the free ion (see Ref. 17). This method was successful producing good agreement with experiment for $\mathrm{H}_{2} \mathrm{O}, \mathrm{NH}_{3}$ and $\mathrm{CH}_{4}$ [18]. In $\mathrm{CaCO}_{3}$ the measured values [19] are $10 \%$ higher than the calculated ones (Table 2).

\section{Experimental details}

In the ECS measurements, the electron spectrometer [1] of the Australian National University at Canberra was used. The incident e-beam is of a well-defined energy and of low thermal spread $(0.3 \mathrm{eV})$; it could be varied from 1 to $40 \mathrm{keV}$; it was used in conjunction with a high resolution spectrometer capable of resolving the small difference in recoil energy $\left(E_{R}=q^{2} / 2 M\right.$, with $q$ the momentum transfer) of the scattered electrons from the
Table 1. Vibrational frequencies of $\mathrm{CO}_{3}{ }^{--}\left(\mathrm{cm}^{-1}\right.$ units) and the calculated fractions $\mathrm{S}_{\mathrm{j}}$ of the kinetic energies of the $\mathrm{C}$ - and $\mathrm{O}$ atoms. The values $v_{1}, v_{2}, v_{3}, v_{5}$ correspond to C-O stretch, C-O$\mathrm{C}$ bend, asymmetric $\mathrm{C}-\mathrm{O}$ stretch, out-of-plane bend. The force constants $\mathrm{k}_{\mathrm{j}}$ (in units of $10^{5} \mathrm{dyne} / \mathrm{cm}$ ) are also listed.

\begin{tabular}{|l|l|c|c|c|}
\hline mode & \multicolumn{1}{|c|}{$v$} & $\mathrm{k}_{\mathrm{j}}$ & $\mathrm{S}_{\mathrm{j}}(\mathrm{C})$ & $\mathrm{S}_{\mathrm{j}}(\mathrm{O})$ \\
\hline$v_{1}$ & 879 & 5.873 & 0 & 0.3333 \\
\hline$v_{2}$ & 1065 & 3.485 & 0.7999 & 0.0667 \\
\hline$v_{3}=v_{4}$ & 1415 & 1.602 & 0.5699 & 0.1433 \\
\hline$v_{5}=v_{6}$ & 680 & 0.596 & 0.2302 & 0.2567 \\
\hline$v_{\mathrm{t}}$ & 200 & -- & 0.2 & 0.2667 \\
\hline$v_{\mathrm{r}}$ & 300 & -- & 0 & 0.3333 \\
\hline
\end{tabular}

different atomic masses of the sample. In a way this spectrometer acts as a mass analyzer separating the peaks of the different masses. It also enables a precise measurement of the energy spread of the electrons scattered from a specific isotope. The spread is due mainly to the Doppler broadening of the electrons caused by the internal and external motions of the atoms of the sample and partly by the instrumental resolution. Fig. 1 shows the Doppler broadened shape of electrons scattered at $135^{\circ}$ from the $\mathrm{O}$ - and $\mathrm{Si}$-atoms (of a $\mathrm{SiO}_{2}$ sample) at $295 \mathrm{~K}$ using a $40 \mathrm{keV}$ incident e-beam. It shows the separation between the peaks of the electron lines scattered from $\mathrm{O}$ and $\mathrm{Si}$-atoms. Here, the Doppler broadening is: $\Delta_{r}=\left(4 E_{R} K_{e} / 3\right)^{1 / 2}$ where $E_{R}=q^{2} / 2 M$ is the recoil energy for scattering from a stationary particle. From the e-scattered spectrum (Fig. 1) and the value of $\Delta_{\mathrm{r}}$ the values of $\mathrm{K}_{\mathrm{e}}(\mathrm{O})$ and of $\mathrm{K}_{\mathrm{e}}(\mathrm{Si})$ were deduced after accounting for the instrumental resolution. The extracted kinetic energies were: $\mathrm{K}_{\mathrm{e}}(\mathrm{O})=66 \pm 3 \mathrm{meV}$ and $\mathrm{K}_{\mathrm{e}}(\mathrm{Si})=$ $70.5 \pm 1.5 \mathrm{meV}$. Note that this result is much higher than the thermal value $3 \mathrm{kT} / 2=38.7 \mathrm{meV}$ at $295 \mathrm{~K}$, the difference is contributed by the zero-point kinetic energy of the external and internal vibrations of the lattice. Here we could not compare the measured $\mathrm{K}_{\mathrm{e}}$ with predictions. To do so, one has to consider the phonon spectrum of $\mathrm{SiO}_{2}$ and calculate the energy fractions $\mathrm{S}_{\mathrm{j}}(\mathrm{O})$ and $\mathrm{S}_{\mathrm{j}}(\mathrm{Si})$ for each frequency; this cannot be carried out within the molecular framework discussed above.

Table 2. Calculated and measured atomic kinetic energy of ${ }^{16} \mathrm{O}$ and ${ }^{12} \mathrm{C}$ (in meV units) in $\mathrm{CaCO}_{3}, \mathrm{H}_{2} \mathrm{O}$ and $\mathrm{O}_{2}$. Measured ECS results [6] for ice are at $118 \mathrm{~K}$ and of $\mathrm{CaCO}_{3}$ at $295 \mathrm{~K}$ [19]. The NCS values $[20]$ are at $5 \mathrm{~K}$.

\begin{tabular}{|l|c|c|c|c|c|}
\hline \multirow{2}{*}{ Sample } & \multicolumn{2}{|c|}{ Calculated } & \multicolumn{3}{c|}{ Measured } \\
\cline { 4 - 6 } & \multicolumn{2}{|c|}{} & ECS & ECS & NCS \\
\cline { 2 - 6 } & $\mathrm{K}_{\mathrm{e}}(\mathrm{O})$ & $\mathrm{K}_{\mathrm{e}}(\mathrm{C}, \mathrm{H})$ & $\mathrm{K}_{\mathrm{e}}(\mathrm{O})$ & $\mathrm{K}_{\mathrm{e}}(\mathrm{C}, \mathrm{H})$ & $\mathrm{K}_{\mathrm{e}}(\mathrm{H})$ \\
\hline $\mathrm{CaCO}_{3}$ & 63.4 & 91.4 & 70 & 101 & -- \\
\hline $\mathrm{H}_{2} \mathrm{O}$ & 52.9 & 154 & 34 & 149 & 152 \\
\hline $\mathrm{O}_{2}$ & 56.4 & -- & -- & -- & -- \\
\hline
\end{tabular}




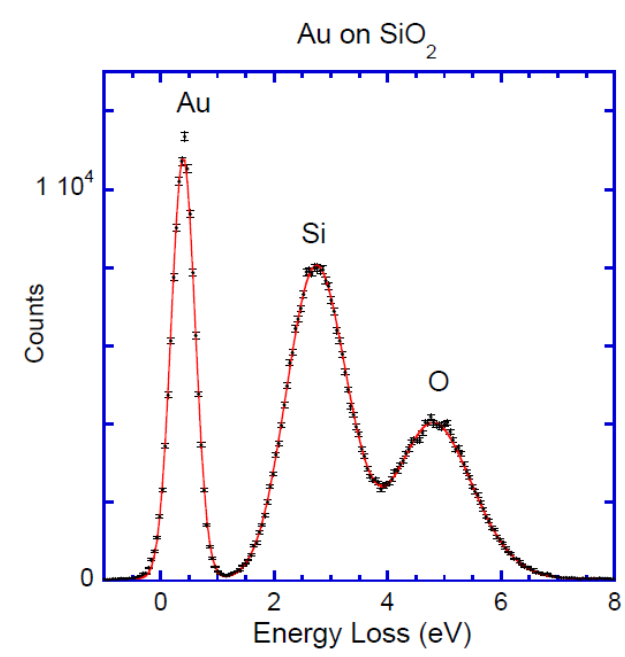

Figure 1. ECS Spectrum (error bars) at $298 \mathrm{~K}$ of $40 \mathrm{keV}$ electrons at $135^{\circ}$ from a $300 \mathrm{~nm} \mathrm{SiO}_{2}$ layer on which $\sim 1 \AA \mathrm{Au}$ layer was evaporated. The fitted spectrum included the natural abundance of the $\mathrm{Si}$ isotopes.

\subsection{The NCS technique}

In the NCS technique one measures the momentum distribution of the $\mathrm{H}$-atoms in a sample such as Kapton [21] from which the atomic kinetic energy is deduced. The method including the data analyses has been described in Ref. 2. The measurements were carried out using the VESUVIO spectrometer of the ISIS pulsed neutron source of Rutherford-Appleton Laboratory, U.K. In this method a pulsed neutron beam in the $\mathrm{eV}$ range is scattered from the sample and the neutron time of flight (TOF) is measured between the $n$-source and the detector. The final energy of the neutron is fixed by passing the scattered beam through a resonance gold absorber whose peak energy is $4.912 \mathrm{eV}$ and a half width at half maximum of $133 \mathrm{meV}$ which limits the instrumental resolution of the system. From the difference between the measured TOF spectra with and without the $\mathrm{Au}$ resonance absorber, the momentum distribution of the scattering atom is obtained as described in detail in [22]. Apart from water, other samples such as graphite and diamond were studied by both techniques. The calculated values in both samples are based on the phonon spectra of the samples. The results (Table 3) show that while in graphite the calculated $\operatorname{Ke}\left({ }^{12} \mathrm{C}\right)$ value is close to the average measured values of the ECS and NCS methods. In diamond the NCS and ECS result are $9 \%$ and 30\% higher than the calculated values. It is possible that a new more accurate NCS measurement of diamond could bring $\mathrm{K}_{\mathrm{e}}(\mathrm{C})$ closer to the calculated one.

It is interesting to note that some anomalous NCS results of the ratio of n-scattering intensities from $\mathrm{H}: \mathrm{O}$ and from $\mathrm{D}: \mathrm{O}$ in $\mathrm{H}_{2} \mathrm{O}$ and $\mathrm{D}_{2} \mathrm{O}$ [23] were repeated using the ECS method at few incident e-energies between $1.5 \mathrm{keV}$ and 6 $\mathrm{keV}$ and no anomaly was observed [4]. In conclusion, the ECS technique is very useful in measuring the atomic kinetic energies which in turn can be used in deducing accurate results of nuclear levels using the self absorption method.
Table 3. Calculated and measured $\mathrm{K}_{\mathrm{e}}\left({ }^{12} \mathrm{C}\right)$ in $\mathrm{meV}$ units at 298 $\mathrm{K}$ in graphite and diamond using the ECS and NCS methods.

\begin{tabular}{|c|c|c|c|}
\hline \multirow{2}{*}{} & \multicolumn{2}{|c|}{ Experimental } & Calculated \\
\cline { 2 - 4 } & ECS [8] & NCS [22] & \\
\hline Graphite & 96.0 & 92.3 & 94.1 \\
\hline Diamond & 99.1 & 120.7 & 93.2 \\
\hline
\end{tabular}

\section{References}

1. M. Vos, Phys. Rev. A. 65, 012703 (2002)

2. S. Imberti, C. Andreani, V. Garbuio, G. Gorini, A. Pietropaolo, R. Senesi, and M. Tardocchi, Nuc. Inst. Meth. Phys. Res. A 552463 (2005)

3. B.J. Gabrys, W. Zajac, J. Mayers and M.S. Kalhoro Appl. Phys. A. 74, 1645 (2002)

4. M. Vos, E. Weigold, R. Moreh, J. Chem. Phys. 138, 044307 (2013)

5. M. Vos, C.A. Chatzidimitriou-Dreismann, T. AbdulRedah and J. Mayers, Nucl. Instr. Meth. Phys. Res. B 227, 223 (2005)

6. R. Moreh, Y. Finkelstein and M. Vos, to be published in Nuc. Inst. Meth. Phys. Res. B. (2014)

7. M. Vos, J. Chem. Phys. 132, 074306 (2010)

8. M. Vos, R. Moreh, K. Tokesi, J. Chem. Phys. 135, 024504 (2011)

9. R. Moreh, W.C.Sellyey, D. Sutton, R. Vodhanel, Phys. Rev. C 31, 2314 (1985)

10. R. Moreh, W.C.Sellyey, R. Vodhanel, Phys. Rev. C. 22, 1820 (1980)

11. R. Moreh, S. Shlomo, and A. Wolf, Phys. Rev. C2, 1144 (1970)

12. W. E. Lamb, Phys. Rev. 55, 190 (1939)

13. Y. Finkelstein, O. Beck, R. Moreh, D. Jäger, U. Kneissl, J. Margraf, H. Maser, and H. H. Pitz, Phys. Rev. B 58, 4166 (1998)

14. R. Moreh, O. Beck, D. Jager, Y. Finkelstein, U. Kneissl, J. Margraf, H. Maser and H.H. Pitz Phys. Rev. B 56, 187 (1997)

15. G. Herzberg, Infrared and Raman Spectra, Van Nostrand Reinhold, New York, 1945

16. Y. Finkelstein and R. Moreh, Chem. Phys. 431, 58 (2014)

17. F. A. Andersen and L. Brecevic, Acta. Chem. Sand. 45, 1019 (1991)

18. M. Vos, K. Tokesi, I. Benko, Micros. Microanal. 19, 576 (2013)

19. R. Moreh, Y. Finkelstein and M. Vos, To be published in Nuc. Inst. Meth. in Phys. Res. B (2014)

20. R. Senesi, G. Romanelli, M.A. Adams and C. Andreani Chem. Phys. 427, 111 (2013)

21. D. Nemirovsky, R. Moreh, Y. Finkelstein and J. Mayers, J. Phys.: Cond. Matt. 13, 5053 (2001)

22. A.L. Fielding, D.N. Timms, J. Mayers, Europhys. Lett. 44, 255 (1998)

23. C. A. Chatzidimitriou-Dreismann, T. Abdul-Redah, R. M. F. Streffer, and J. Mayers, Phys. Rev. Lett. 79, 2839 (1997) 
